\title{
Management of proximal penile prosthetic cylindrical complications: a novel direct crural approach
}

\author{
Ahmed S. Zugail ${ }^{1,2}$, Maher Abdessater ${ }^{3,4,5^{*}}$, Abdulmajeed Althobity ${ }^{1}$, Johnny Boustany ${ }^{6}$, Mabel Nuernberg ${ }^{4}$,
} Abdalla Alhammadi ${ }^{1}$ and Sébastien Beley ${ }^{1}$

\begin{abstract}
Introduction: Patients with proximal penile prosthetic cylindrical complications (PPPCC) can be treated with a direct crural technique without using the original traditional approach. In this article we present our novel direct crural approach for management of patients with PPPCC.

Materials and methods: Between 2014 and 2019, data were retrospectively collected from 13 patients who underwent surgical revision using our novel direct crural approach for PPPCC. The procedure commences with identification of the affected zone. The patient is in a low lithotomy position. A 2-centimeter longitudinal incision is made directly over the affected site. Dissection is carried down through Colles' fascia, followed by a longitudinal incision through the tunica albuginea at the proximal part of the affected cylinder. Via the incision we can deliver out the cylinder and manage its problem.

Results: Mean operative time was $40 \mathrm{~min}$. No intra or post-operative complications were reported. All patients (Mean age $=57$ ) were discharged on the same day. Postoperative follow-up found correction of all existing deformities at month 1,3 and 6 . All patients were satisfied and reported less pain and faster recovery than the first procedure.

Conclusion: Our technique, which can be used for all types of penile prosthesis, is both feasible and safe. It may simplify PPPCC revision by avoiding adhesions below the original incision, without jeopardizing the already implanted materials or the urethra. It may also improve patients' safety and satisfaction, by reducing iatrogenic injury and post-operative recovery time.
\end{abstract}

Keywords: Crural approach, Erectile dysfunction, Penile implantation, Penile prosthesis, Prosthesis failure

\footnotetext{
* Correspondence: maher.abdessater@gmail.com

${ }^{3}$ Department of Urology, Sorbonne Université, APHP, Pitié Salpêtrière, 83 bvd Hopital, 75013 Paris, France

${ }^{4}$ Faculty of Medicine, Sorbonne University, Paris, France

Full list of author information is available at the end of the article
}

(C) The Author(s). 2020 Open Access This article is licensed under a Creative Commons Attribution 4.0 International License, which permits use, sharing, adaptation, distribution and reproduction in any medium or format, as long as you give appropriate credit to the original author(s) and the source, provide a link to the Creative Commons licence, and indicate if changes were made. The images or other third party material in this article are included in the article's Creative Commons licence, unless indicated otherwise in a credit line to the material. If material is not included in the article's Creative Commons licence and your intended use is not permitted by statutory regulation or exceeds the permitted use, you will need to obtain permission directly from the copyright holder. To view a copy of this licence, visit http://creativecommons.org/licenses/by/4.0/ The Creative Commons Public Domain Dedication waiver (http://creativecommons.org/publicdomain/zero/1.0/) applies to the data made available in this article, unless otherwise stated in a credit line to the data. 


\section{Resume}

Introduction: Les complications concernant les cylindres proximaux des prothèses péniennes peuvent être traitées par un abord crural sans avoir recours à l'incision péno-scrotale classique. Dans cet article, on décrit une nouvelle voie d'abord crurale directe pour la prise en charge des complications prothétiques proximale.

Matériels and Méthodes: II s'agit d'une étude rétrospective, entre 2014 et 2019, sur 13 patients ayant eu une correction chirurgicale par voie d'abord crurale, suite à des complications prothétiques cylindriques proximales. La zone affectée est. identifiée avant le début de l'opération. En position de lithotomie, une incision longitudinale de $2 \mathrm{~cm}$ est. réalisée directement au niveau de la zone atteinte. La dissection se fait à travers le fascia de Colles, suivie d'une incision longitudinale de la tunique albuginée à la partie proximale du cylindre atteint. A travers cette incision, le cylindre peut être retiré et la gestion de son problème sera aisée.

Résultats: Le temps opératoire moyen était de 40 min. Aucune complication durant ou après l'opération n'a été rapportée. Tous les patients (âge moyen $=57$ ans) sont sortis de l'hôpital le même jour. Le suivi postopératoire a révélé une correction de toutes les déformations existantes après 1, 3 et 6 mois. Tous les patients étaient satisfaits et ont rapporté moins de douleur et une durée de convalescence plus courte qu'après la première procédure.

Conclusion: Notre technique chirurgicale, applicable pour tout type de prothèses péniennes, est. à la fois faisable et sans risque majeur. Elle simplifie la reprise chirurgicale des complications de prothèses péniennes proximales sans avoir recours à l'incision initiale, ce qui évite les adhérences et de mettre en danger le matériel implanté et l'urètre. Elle peut également améliorer la sécurité et la satisfaction des patients en réduisant les blessures iatrogènes et le temps de récupération postopératoire.

Mots clés: Voie d'abord crurale, Dysfonction érectile, Implant pénien, Prothèse pénienne, Complications prothétiques

\section{Introduction}

Penile prosthesis technology and surgical procedures have been evolving since the early 1970's with continual improvements in surgical outcomes. Worldwide, penile prosthesis is considered a gold standard treatment for men with organic erectile dysfunction who have failed less invasive managements and are motivated to pursue treatment and continued sexual activity [1]. Currently, the European Association of Urology indicates inflatable penile prosthesis in case of inadequate treatment outcome after phospodiesterase 5 inhibitor, topical/intraurethral alprotadil, vacuum device, low intensity shock wave treatment, and intracavernosal injections for erectile dysfunction [2]. While penile prosthesis is largely successful with low infection rates and high patient satisfaction rates, a small number of patients experience surgical or mechanical complications. Urologists performing penile prosthesis operations must be familiar with their complications, revision procedures, reconstruction techniques and salvage methods. While recent data have shown satisfactory operative rates for primary implantation of $96 \%$ at 5 years and $60 \%$ at 15 years [3], refining the surgical technique used for managing penile prosthetic cylindrical complications may further improve patient safety and satisfaction.

Simple and applicable for all types of penile prosthesis, a direct crural approach may be an effective technique for managing proximal penile prosthetic cylindrical complications while improving patient safety.
The aim of this article is to present our novel surgical technique using a direct crural approach to gain access to the proximal corpora i.e. crus of the penis pl. crura and repare cylinder complications, avoiding the original penoscrotal or infrapubic incision.

\section{Methods and materials}

Data were retrospectively collected from all 13 patients who underwent consecutively our novel direct crural approach for proximal penile prosthesis cylindrical complication revision in our Urology Center in central Paris, between 2014 and 2019. Institutional review board approval was obtained before applying our novel technique and written informed consent was obtained from all patients. This article follows the TIDieR (Template for Intervention Description and Replication) reporting guidelines for medical interventions [4].

Two Urologists, one senior and one fellow, both operated all 13 patients in our Urology Center. The procedure was standardized then minimally adapted to each patient's specified anatomy and prosthesis. The procedure was not modified during the course of study. Intervention adherence and fidelity was strong.

The direct crural approach was used for surgical revision when one cylinder was undersized or oversized. The technique was not a replacement for glansplasty in patients with hypermobile glans (frequent with Supersonic transporter (SST) deformities, two undersized cylinders or inadequate glans support). 
No patient had proximal cylinder complications during the initial implant. No imaging was necessary before the surgery. Postoperative follow-up clinical examination was conducted by one of the two Urologists at month 1 , 3 and 6. Complications were evaluated by clinical exam and all proximal cylinder complications were noted during follow-up.

\section{Surgical technique}

Patients receive general, spinal or local anesthesia and are placed in a low lithotomy position (Fig. 1). Skin is shaved and prepped for $10 \mathrm{~min}$ with an iodine soapy scrub. Then, an alcoholic-iodine solution is swabbed twice followed by sterile draping using an antimicrobial incise drape to cover the area of scrotum and perineum while keeping the anus out of the surgical field. An intravenous dose of a prophylactic antibiotic is administered. The procedure commences with identification of the affected site and the nature of the deformity. A 2-centimeter longitudinal incision is made over the affected site (crus of the penis) (Fig. 2). The dissection is carried down through Colles' fascia. A Scott's retractor is used and large blunt skin hooks are attached to expose the corpora and facilitate further dissection. Then, a longitudinal incision through the tunica albuginea is made at the proximal part of the affected cylinder (Fig. 3a-b). A monofilament absorbable suture is placed on each side of the corporotomy as a stay suture (Fig. 3c). From this incision we can deliver out the cylinder (Fig. 3d) and manage the existing prosthetic cylinder. Previously oversized malleable or hydraulic cylinders are partially or entirely removed. Undersized cylinders are corrected either by replacing the rear tip extender (RTE) with a longer one or simply by adding one if no RTE

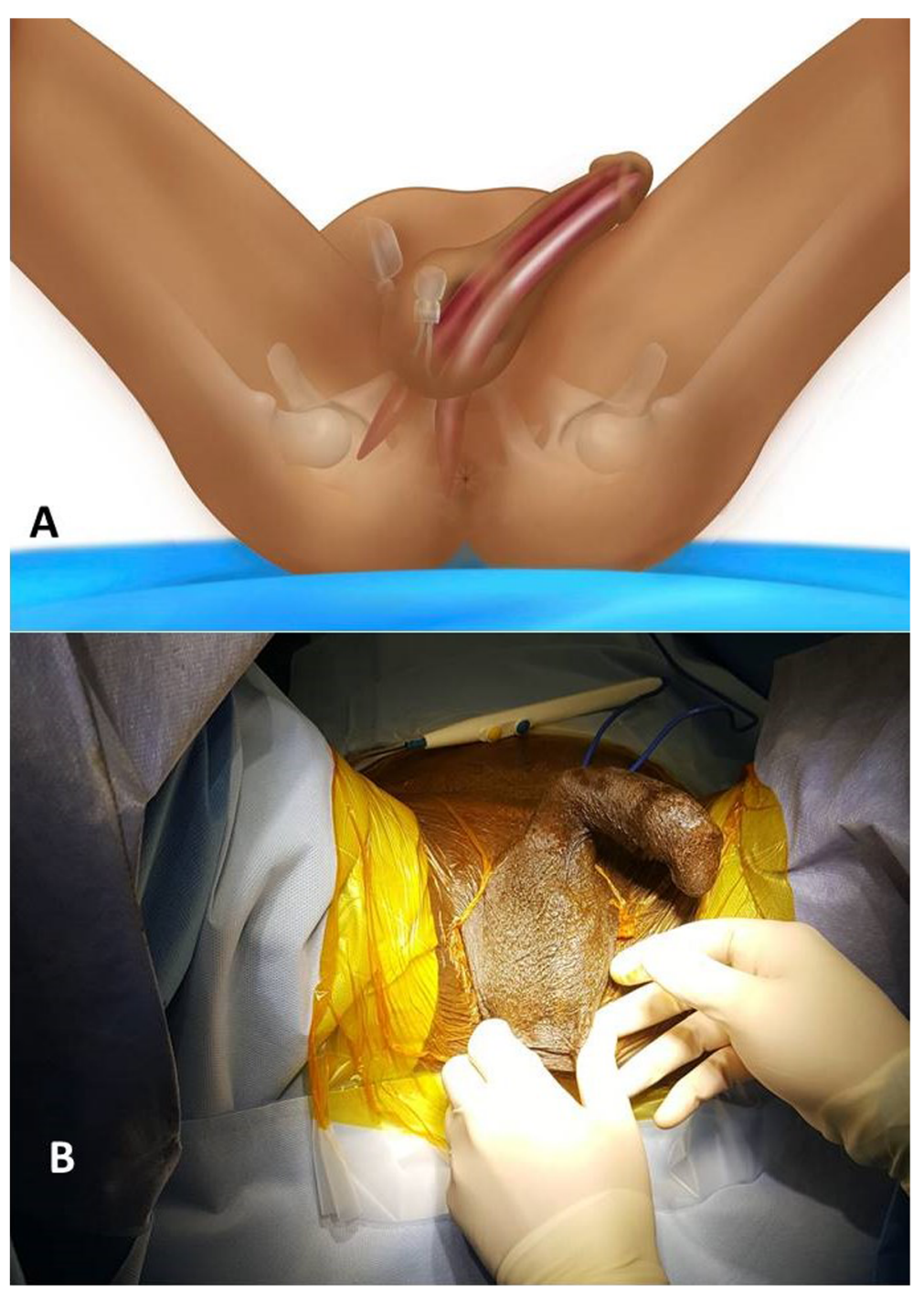

Fig. 1 Artwork (a) and photo (b) showing the lithotomy position 

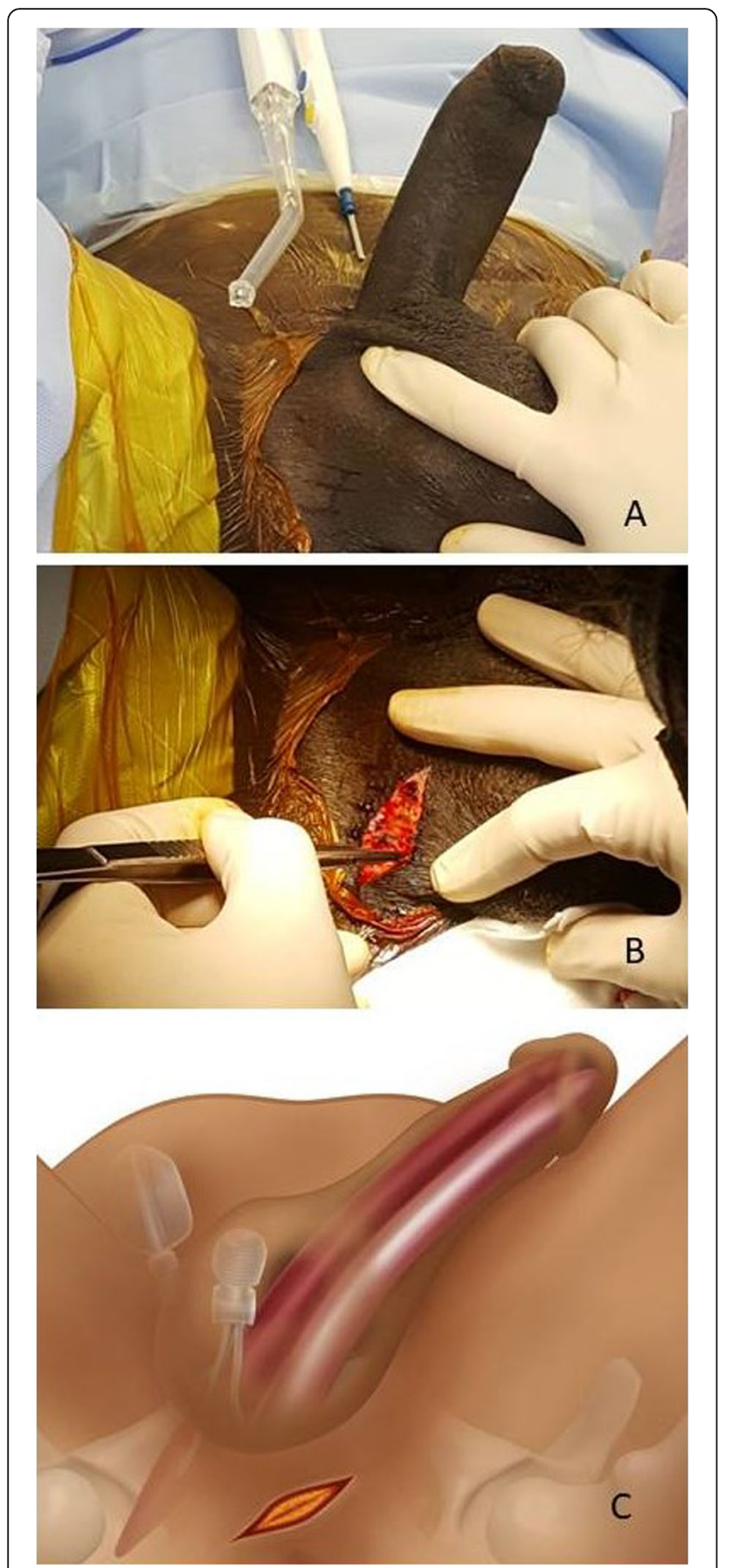

Fig. 2 The incision of our novel technique. a Incisional line drawn by a sterile surgical marker and the actual longitudinal incision of 2cm over the affected cylinder (b). c Artwork revealing the underlying anatomical structures around the incision

was initially used. This incision also allows us to repair proximal cross-over and to re-position a proximally migrated cylinder or RTE back into the corpora. Then, the tunica albuginea is sealed carefully by a running and tight 3-0 monofilament absorbable stitches. The fascia and skin are tightened by 3-0 absorbable running sutures.

Patients are discharged the same day of the intervention in accordance with the Chung criteria and with appropriate pain management prescription. They are advised to take a full rest for 1 week and avoid bicycle riding or similar activities. In order to ensure adequate healing time of the tunica albuginea, patients are allowed to resume using their prosthesis 6 weeks after the surgery. The wounds are cleaned and dressed daily by a nurse using normal saline until full healing. Wound examination is conducted at all post-operative follow-up visits by the two Urologists.

\section{Results}

Data were retrospectively collected from 13 patients who underwent our novel direct crural technique between October 2015 and March 2019. The mean age was 57 years, and ranged from 48 to 69 years. The mean body mass index (BMI) was $25 \mathrm{~kg} / \mathrm{m}^{2}$ and ranged from 20 to $31 \mathrm{~kg} / \mathrm{m}^{2}$. Revision procedure indications included glans bowing (SST deformity) in 6/13 (46\%), proximal erosions in 4/13 (31\%) and oversized cylinders with an S-shaped deformity causing pain in 3/13 (23\%). No patient had previous undergone complication revision, artificial urinary sphincter insertion, or radiotherapy. Indications for the initial implant placement included vasculogenic erectile dysfunction in 6/13 (46\%) and post-prostatectomy erectile dysfunction in $7 / 13$ (54\%). The Initial incision was infrapubic in $8 / 13(61 \%)$ and penoscrotal in 5/13 (39\%). The mean interval between initial implant placement and revision was 3 months. No patient had proximal cylinder crossovers upon intraoperative examination. Penile prosthesis model types included $\operatorname{Titan}^{\circ}$ Touch in 10/15 (77\%) and Genesis ${ }^{\circ}$ Malleable Penile Prosthesis in 3/13 (23\%) (both Coloplast Group, Humlebaek, Denmark). Prothesis length ranged from 16 to $22 \mathrm{~cm}$, mean lenght was 19.7 $\mathrm{cm}$. Penile prosthesis and penis length difference ranged from 1 to $3 \mathrm{~cm}$ mean difference was $1.5 \mathrm{~cm}$.

All operations were successful with no difficulties encountered. Surgery duration ranged from 28 to $50 \mathrm{~min}$, mean duration was $40 \mathrm{~min}$. All 13 patients reported full satisfaction after the surgery based on the satisfaction domain of the international index of erectile function (IIEF); this domain represents the sum of the responses to questions $7,8,13$, and 14, including intercourse satisfaction, intercourse enjoyment, overall satisfaction with sex, and satisfaction with the sexual partner. The maximum score of this domain is 20. All the patients had a score of more than 15 . The patients also reported less post-operative pain and faster recovery as compared to the first procedure. All SST and S-deformities were resolved. 

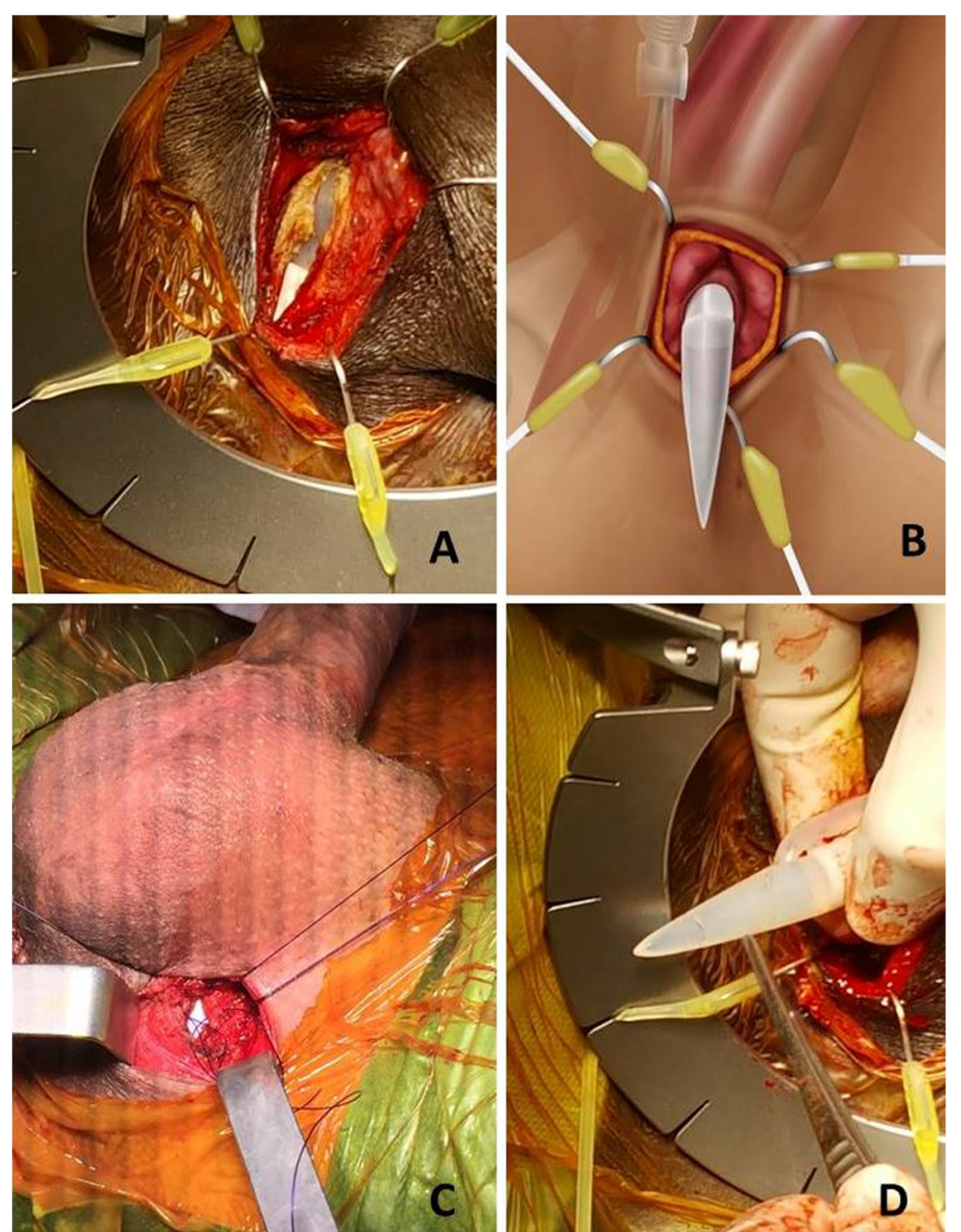

Fig. 3 The steps of the surgical technique. a A photo showing the Scotts retractor in place exposing the incision of tunica albuginea with the help of multiple large blunt skin hooks. b Artwork revealing the underlying anatomical structures with the hooks in place. $\mathbf{c}$ A photo showing a stay 3-0 monofilament absorbable suture on each side of corporotomy that reveals the cylinder (Whitish zone). $\mathbf{d}$ The proximal end of the cylinder is easily delivered manually in this photo

No complications were reported during the procedure, notably there were no iatrogenic events (urethral injuries, damage to the scrotal pump or tubing of inflatable penile prosthesis). No excessive bleeding $(>100 \mathrm{~mL})$ was reported. No infections, hematomas or wound complications were reported during the median follow-up period of 6 months.

\section{Discussion}

Surgical techniques and devices for IPP implant have evolved, improving patient safety and satisfaction [5], since Scott et al. described the first inflatable penile prosthesis (IPP) implantation in 1973 [6]. Complications occur most frequently in patients with diabetes, spinal cord injury or immunosuppression [7]. Revision procedures after IPP implantation are most frequently due to cosmetic or erosive etiologies as opposed to mechanical issues [8]. As increasing numbers of patients with erectile dysfunction undergo penile prosthetic implantation, unusual complications are being reported. This highlights the need for new, simpler and safer revision techniques [9].

Accessing the corpora through direct scrotal incision may be beneficial as it avoids the prior penoscrotal or high scrotal incisions and surgical difficulties due to adhesions and fibrosis from the prior intervention. However, the risk of iatrogenic injury due to the direct scrotal approach is nonnegligible. The scrotal pump or tubing may be threatened. The biofilm capsule may be violated during dissection, possibly leading to post-operative infection. Scrotal edema or hematoma may prolong the postoperative recovery period and delay sexual activity resumption. 
The direct crural approach may be an alternative surgical method useful to treat penile prosthetic cylinder complication and manage existing abnormalities. Prosthetic cylinder revision using our technique may be safe and efficient; the single crural incision provides a more superficial access to the corpora with less tissue manipulation as compared to the traditional scrotal approach. Our novel direct crural approach facilitates surgical repair and provides better surgical field exposure and thus a better anatomical perspective. The technique can be used for both inflatable and semirigid (malleable) penile prostheses. It is useful in revising proximal penile prosthetic cylindrical complications such as oversized cylinders causing S-shaped deformities, undersized cylinders causing incompletely dilated corpora and Glans Bowing (Penile supersonic transporter [SST] deformities), and proximal cylinder erosions beneath the skin and proximal cylinder crossovers. Both iatrogenic injury and post-operative recovery time may be reduced as the approach avoids adhesions below the original incision, without jeopardizing the already implanted materials or the urethra. To note that it is widely demonstrated that revision procedures of penile prosthesis are at higher risk of complications. This is due first to corporal fibrosis or infection. In this context, studies indicate a complications rate (especially infectious ones) ranging from 8 to $12 \%$ [10-13].

The reduction of surgical time is possibly one of the main reasons for success of our technique, with the consequent reduction of the risk of infection. The prosthetic surgeon will always prefer the simple, fast and clean procedure.

This direct crural approach has several limitations. First, it is not appropriate for numerous penile prosthetic cylinder complications including distal corporal erosions beneath the skin or glans deformities that need plication. Thus it could not be a good option in case of cylinder crossing due to the difficulty in controlling the rest of the corpus cavernosum It almost invariably requires bilateral access, regardless of the type of prosthesis, being a problem of incorrect implant size. Second, this approach allows only a limited exploration of the distal corpora, an essential step in achieving successful outcomes. It is not adapted to patients requiring implantation of a new device and it should be further explored in patients presenting prosthetic cylinder complications requiring a bilateral approach. Finally, we would highlight that here, we are only considering a very small series from a non-comparative study which preclude conclusions on a large scale.

\section{Conclusion}

Our novel direct crural approach is safe, simple and effective in managing certain penile prosthetic cylindrical complications requiring access to the proximal cylinder. This approach can be used for both inflatable and semi rigid (malleable) penile prostheses. It avoids adhesions below the original incision, without jeopardizing the already implanted materials or the urethra. However, further exploration of this technique is required before it may be used as a standard surgical method.

\section{Abbreviations}

BMI: Body mass index; IIEF: International index of erectile function; PPPC C: Proximal penile prosthetic cylindrical complications; RTE: Rear tip extender; SST: Supersonic transporter; TIDieR: Template for intervention description and replication

\section{Acknowledgments}

Not applicable.

\section{Authors' contributions}

All seven authors made substantial contributions to conception and design, acquisition of data and analysis and interpretation of data; Authors participated in drafting the article and revising it critically for important intellectual content. Authors gave final approval of the version to be submitted. Each author participated sufficiently in this work and takes public responsibility for appropriate portions of the content. The authors read and approved the final manuscript.

Funding

Authors declare no sources of funding for this article.

Availability of data and materials

Not applicable.

Ethics approval and consent to participate

Not applicable.

Consent for publication

Written informed consent was obtained from all the patients.

\section{Competing interests}

Dr. Sebastien Beley works as a consultant for Coloplast and in AdvanceMedical Technology companies. Otherwise, we have no conflict of interestsnor financial interests to be disclosed.

\section{Author details}

${ }^{1}$ Department of Urology, La Croix Saint Simon Hospital, Paris, France. 2Department of Urology, Faculty of Medicine in Rabigh, King Abdulaziz University, Jeddah, Saudi Arabia. ${ }^{3}$ Department of Urology, Sorbonne Université, APHP, Pitié Salpêtrière, 83 bvd Hopital, 75013 Paris, France. ${ }^{4}$ Faculty of Medicine, Sorbonne University, Paris, France. ${ }^{5}$ Department of Urology, La Pitié Salpêtrière University Hospital, Paris, France. ${ }^{6}$ Department of Urology, Henri Mondor University Hospital, Créteil, France.

Received: 22 June 2020 Accepted: 4 October 2020

Published online: 03 November 2020

References

1. Carson CC, Mulchy JJ, Govier FE. Efficacy, safety, and patient satisfaction outcomes of the AMS $700 C X$ inflatable penile prosthesis: results of a long term multicenter study. J Urol. 2000;164:376-80.

2. Hatzimouratidis K, Giuliano F, Moncada I, Muneer A, Salonia A, Verze P. EAU Guidelines on erectile dysfunction, premature ejaculation, penile Curvature and Priapism. Edn. presented at the EAU Annual Congress Barcelona 2019. ISBN 978-94-92671-04-2.

3. Rajpurkar A, Dhabuwala CB. Comparison of satisfaction rates and erectile function in patients treated with sildenafil, intracavernous prostaglandin E1 and penile implant surgery for erectile dysfunction in urology practice. J Urol. 2003;170:159-63. 
4. Hoffmann T, Glasziou P, Boutron I, Milne R, Perera R, Moher D, Altman D, Barbour V, Macdonald H, Johnston M, Lamb S, Dixon-Woods M, McCulloch P, Wyatt J, Chan A, Michie S. Better reporting of interventions: template for intervention description and replication (TIDieR) checklist and guide. BMJ. 2014;348:g1687.

5. Antonini G, Busetto GM, De Berardinis E, Giovannone R, Vicini P, Del Giudice F, Conti SL, Gentile V, Perito PE. Minimally invasive infrapubic inflatable penile prosthesis implant for erectile dysfunction: evaluation of efficacy, satisfaction profile and complications. Int J Impot Res. 2016;1:4-8.

6. Scott FB, Bradley WE, Timm GW. Management of erectile impotence: use of implantable inflatable prosthesis. Urology. 1973;2:80-2.

7. Phé V, Rouprêt M, Ferhi K, Traxer O, Haab F, Beley S. Etiology and management of erectile dysfunction in patients with diabetes mellitus. Prog Urol. 2009;19(6):364-71.

8. Henry GD, Wilson SK, Delk JR 2nd, Carson CC, Wiygul J, Tornehl C, Cleves MA, Silverstein A, Donatucci CF. Revision washout decreases penile prosthesis infection in revision surgery: a multicenter study. J Urol. 2005;173:89-92.

9. Alhammadi A, Abdessater M, Althobity A, et al. Alternative surgical approach for inflatable penile prosthesis removal. Basic Clin Androl. 2020;30: 6. https://doi.org/10.1186/s12610-020-00104-6.

10. Martínez-Salamanca Jl, Mueller A, Moncada I, Carballido J, Mulhall JP. Penile prosthesis surgery in patients with corporal fibrosis: a state of the art review. J Sex Med. 2011;8:1880-9.

11. Henry GD, Donatucci CF, Conners W, Greenfield JM, Carson CC, Wilson SK, Delk J, Lentz AC, Cleves MA, Jennermann CJ, Kramer AC. An outcomes analysis of over 200 revision surgeries for penile prosthesis implantation: a multi-center study. J Sex Med. 2012;9:309-15.

12. Chung E. Penile prosthesis implant in the special populations: diabetics, neurogenic conditions, fibrotic cases, concurrent urinary continence surgery, and salvage implants. Asian J Androl. 2020;22(1):39-44. https://doi.org/10. 4103/aja.aja_127_19.

13. Carvajal A, Benavides J, García-Perdomo HA, et al. Risk factors associated with penile prosthesis infection: systematic review and meta-analysis. Int J Impot Res. 2020. https://doi.org/10.1038/s41443-020-0232-x.

\section{Publisher's Note}

Springer Nature remains neutral with regard to jurisdictional claims in published maps and institutional affiliations.

Ready to submit your research? Choose BMC and benefit from:

- fast, convenient online submission

- thorough peer review by experienced researchers in your field

- rapid publication on acceptance

- support for research data, including large and complex data types

- gold Open Access which fosters wider collaboration and increased citations

- maximum visibility for your research: over $100 \mathrm{M}$ website views per year

At BMC, research is always in progress.

Learn more biomedcentral.com/submissions 